\title{
Reliability and validity of the Repeatable Battery for the Assessment of Neuropsychological Status in community- dwelling elderly
}

\author{
Yan Cheng', Wenyuan $\mathrm{Wu}^{1}$, Jiaqi Wang ${ }^{1}$, Wei Feng ${ }^{1}$, Xiangwei $\mathrm{Wu}^{1}$, Chunbo $\mathrm{Li}^{2}$
}

1Department of Psychiatry, Tongji Hospital, Shanghai, China

2Department of Biological Psychiatry, Shanghai Mental Health Centre, Shanghai Jiao

Tong University School of Medicine, Shanghai, China

Submitted: 8 November 2011

Accepted: 18 December 2011

Arch Med Sci 2011; 7, 5: 850-857

DOI: 10.5114/aoms.2011.25561

Copyright $\odot$ Termedia \& Banach

\begin{abstract}
Introduction: The Repeatable Battery for the Assessment of Neuropsychological Status (RBANS) is a widely used screening instrument in neuropsychological assessment and is a brief, individually administered measure. The present study aims to assess the reliability and validity of the Chinese version of the RBANS in community-dwelling elderly.

Material and methods: All subjects come from the community-dwelling elderly in Shanghai, China. They completed a questionnaire concerning demographic information, the mini-mental state examination (MMSE) and the Chinese version of the RBANS. To test for internal consistency, Cronbach's $\alpha$ was calculated for all six RBANS indices. Correlations between each of the RBANS and MMSE subtests were conducted to measure the concurrent validity. A confirmatory factor analysis (CFA) was conducted to test the construct validity.

Results: The final sample of participants included 236 community-dwelling elderly. The mean total score on the RBANS was $86.02( \pm 14.19)$. The RBANS total score showed strong internal consistency $(r=0.806)$, and the coefficient $\alpha$ value for each of the RBANS scales ranged from 0.142 to 0.727 . The total RBANS score was highly correlated with that of the MMSE $(r=0.594, p<0.001)$, and the RBANS subtests also demonstrated strong correlations with most of the MMSE subtests. The results of the CFA indicated an acceptable fit between the Chinese version of the RBANS and the original.

Conclusions: The Chinese version of the RBANS had relatively good reliability and validity in a community-dwelling elderly sample. It may be a useful screening instrument for conducting cognitive assessments in community-dwelling elderly.
\end{abstract}

Key words: Repeatable Battery for the Assessment of Neuropsychological Status, reliability, validity, neuropsychological assessment, the elderly.

\section{Introduction}

The assessment of cognitive change is an important task for neuropsychologists, especially those working in geriatric settings [1]. Cognitive impairment is a common and significant feature of the elderly [2]. The ability to identify stability or improvements in cognitive function is a valuable clinical skill [3]. Cognitive assessment is widely used for three types of indications: first, screening for cognitive impairment; second, discriminative diagnosis of cause; third, rating of severity of disorder, or monitoring of disease progression [3, 4]. An instrument that could be used

\author{
Corresponding author: \\ Prof. Wenyuan Wu \\ Department of Psychiatry \\ Tongji Hospital \\ Shanghai, China \\ Phone: +862166111487 \\ Fax: +86 2156947291 \\ E-mail: wuwy@tongji.edu.cn
}


to screen for cognitive status and to provide information about prognosis in the elderly would be of great value. However, the cognitive assessment of geriatric individuals is often associated with a variety of difficulties [5]. For instance, older adults are more prone to fatigue [5]. They pay more attention to physical health and have little interest in time-consuming neuropsychological evaluations, such as the Wechsler Adult Intelligence Scale-III and the Wechsler Memory Scale-III [5]. A wide range of tools has been developed for cognitive assessment [3]. These vary from brief screening tools that take less than $1 \mathrm{~min}$ to complete to professional neuropsychological assessments that take several hours [3]. The appropriate choice of tools depends on the time available and the purpose of the assessment [3].

The Repeatable Battery for the Assessment of Neuropsychological Status (RBANS) is a widely used screening instrument in neuropsychological assessment [6, 7]. The RBANS is a brief, individually administered measure [5]. It consists of 12 subtests, most of which are similar to individual neuropsychological measures [5]. The instrument takes some of the difficulties inherent in the assessment of older adults into account [5]. In this way, the RBANS has the benefit of being brief and tolerable to complete as compared with other neuropsychological batteries, while providing more detailed information than many other screening measures such as the Dementia Rating Scale. The normative information for the RBANS provided in the manual is a US nationwide, population-based standardization with adults aged from 20 to 89 years old [5]. It has been demonstrated to be a valid and reliable instrument for detecting cognitive deficits across a range of age levels and diagnostic groups [5].

However, the RBANS has not been used widely in China. In China, the largest developing country in the world, aging has become a social problem.
Therefore, a practical measure for cognitive assessment has wide potential use. It has been proven that level of education would account for a statistically significant portion of the variance across performance on the RBANS and the individual indices [8-10]. The mean education level in developing countries is lower than that in developed countries. Thus, we need to present data confirming the reliability and validity of the RBANS in community-dwelling elderly in China to support the wide application of this instrument in China in the future.

\section{Material and methods}

This study received ethics approval from the Ethics Committee of Tongji Hospital.

\section{Participants}

The original data set consisted of 300 community-dwelling elderly residing near Tongji Hospital in Shanghai. Thirty-one individuals were excluded from the study because of physical deficits (e.g., visual impairment, hearing impairment, motor dysfunction) and severe mental diseases (e.g., schizophrenia, depression) to ensure that participants could fully participate in standardized administrations of the RBANS. Twenty-seven subjects failed to follow up because of withdrawal from the study, moves to other locations, incorrect telephone numbers, or death. Six questionnaires were unable to be used because of incomplete information. The final sample of participants included 236 community-dwelling elderly (Figure 1).

\section{Procedures}

Three communities were selected around Tongji Hospital. Most of the people living in the selected communities are older adults, thereby supplying us with a large baseline population. Neighbourhood committees from each community were asked to

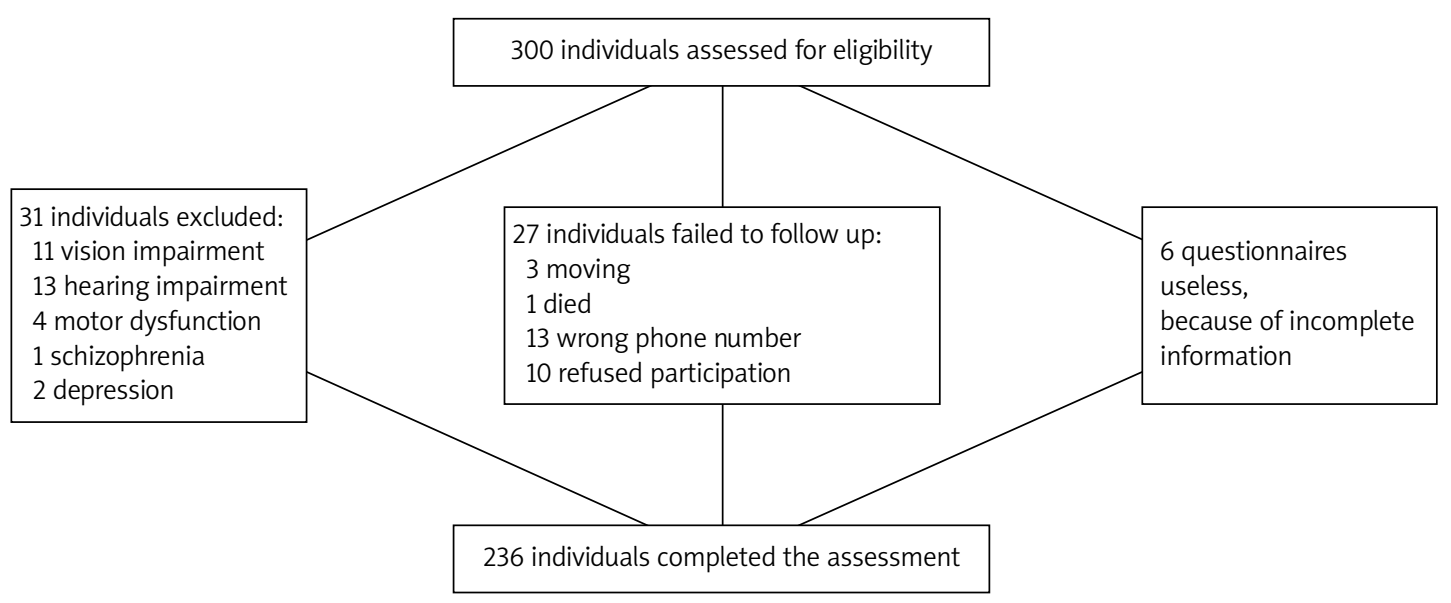

Figure 1. Flow of participants through the trial 
supply three quiet rooms and the capacity to broadcast our study purpose throughout the whole community. Those elderly who expressed interest in our study came to the neighbourhood committee and participated in a face-to-face interview. All participants completed the Informed Consent Form, a list of contact information, and a questionnaire that inquired about demographic information, medical conditions, physical symptoms, and the mini-mental state examination (MMSE). Then, we made an appointment by telephone and completed a face-to-face assessment using a brief neuropsychological screening battery, the RBANS, at Tongji Hospital in Shanghai. The administration and scoring of the RBANS was conducted as defined in the manual in a quiet room in Tongji Hospital by investigators who had received training by a clinical psychologist. The RBANS was administered according to standardized procedures.

\section{Measures}

\section{The RBANS}

The RBANS generates six Index Scores: a total scale index; and five domain-specific index scores used to assess immediate memory, visuospatial/ constructional abilities, language, attention, and delayed memory [5]. With the exception of Delayed Memory, a component that is based on four subtests, each of the other four Index Scores is based on two subtests. The Immediate Memory Index consists of the List Learning and Story Memory subtests; the Visuospatial/Constructional Index consists of the Figure copy and Line Orientation subtests; the Language Index consists of the Picture Naming and Semantic Fluency subtests. Semantic fluency is the ability to form and express words compatible with required criteria and is a good indicator of frontal lobe dysfunction [11]. The Attention Index consists of the Digit Span and Coding subtests; the Delayed Memory Index consists of the List Recall, List Recognition, Story Recall, and Figure Recall subtests [5]. The RBANS was designed with additional forms used to evaluate disease progression or outcome testing of therapeutics [5]. The availability of two forms could avoid practice effects not only in the measurement of disease progression but also in the screening for symptomatic improvements in response to therapeutic interventions [5]. All participants in the present study received form A of the RBANS.

The translation of the RBANS, English version, into Chinese was carried out in several steps. First, the translation was conducted by an independent translator (a psychiatrist with Chinese as the native language, proficient in English). Second, the Chinese version was discussed within the research group. Following this step, a back-translation was performed by a professional non-psychiatrist translator and was again discussed within the research group. The final Chinese version of the RBANS was adopted in the present study. To be more culturally consistent, we changed "in Cleveland, Ohio" in the story memory and story recall test into "in China, Fujian". The change did not alter the level of difficulty of the text with respect to reading comprehension.

\section{The MMSE}

The MMSE is the most commonly used cognitive screening tool in the area of psychogeriatrics in the USA, Canada, and the UK [12]. It is a 30-point assessment tool [13] that takes about $8 \mathrm{~min}$ to perform with older patients (range from $4 \mathrm{~min}$ to $21 \mathrm{~min}$ ) [14]. The MMSE correlates well with a number of cognitive screening tests and neuropsychological tests [4]. The Chinese version of the MMSE has reasonable sensitivity and specificity $[15,16]$. The MMSE consists of 12 scores: a Total Score and 11 Index Scores. The 11 index scores are Temporal orientation, Place orientation, Immediate memory, Calculation, Delayed memory, Naming, Tongue twister, Reading comprehension, Command execute, Sentence-making and Figure copy [17]. Thus, we chose the MMSE as the standard by which to measure the concurrent validity of the RBANS.

\section{Statistical analysis}

The database was established by EpiData3.0. Descriptive statistics were generated to examine the performances on the RBANS and MMSE. Pearson's correlation coefficients were calculated to determine any associations between age, education, gender and RBANS index scores. Scale reliabilities, specifically the internal consistency of the six scales, were assessed by calculating Cronbach's $\alpha$. The concurrent validity of the RBANS was assessed by assessing correlations between each of the RBANS and MMSE subtests. Confirmatory factor analysis (CFA) was performed using LISREL 8.7 to test construct validity.

\section{Results}

\section{Demographic data}

The final sample of participants included 236 community-dwelling elderly ( $M$ age $=70.32$ years, $S D=3.64$, range $=62-77$ years; $M$ education $=9.96, \mathrm{SD}=3.78$, range $=1-18$ years $)$. One woman was of Mongolian nationality; all remaining participants were of the Han nationality. Additional demographic characteristics for the sample are presented in Table I. 
To examine the impact of age and education, Pearson correlations were calculated with the RBANS total and index scores (see Table II). A significant relationship was noted between education and all six RBANS indices (all $p$ values $<0.01$ ), suggesting a modest, expectable association between cognitive performance and educational levels. Five significant correlations were observed with age; the exception was the language index. It showed that the decline of language performance associated with age was inconspicuous.

In contrast to other research $[9,10]$, male and female patients differed in the total score, visuospatial/constructional index and attention index, where men performed significantly better (see Table II). We compared the level of education of males (11.12 \pm 3.60 years) with females ( $8.70 \pm 3.57$ years), and the results showed a significant correlation $(t=5.187, p<0.001)$. Thus, we believe that the differences caused by gender may be due to the differences in education level.

\section{Performance of RBANS}

For the 236 elderly, the mean total score on the RBANS was 86.02 ( \pm 14.19$)$. This result is nearly one standard deviation lower than the American normative data [18] and is lower than the level of performance observed in other reports [7, 19-21]. The differences observed in our study may be due to the low level of education, which was strongly correlated with the RBANS performance (Table III).

\section{Reliability of the RBANS}

To test the internal consistency of the RBANS, Cronbach's $\alpha$ was calculated for all six RBANS indices. The RBANS total score showed strong internal consistency $(r=0.806)$ in our elderly sample, and the coefficient $\alpha$ value for each of the RBANS scales ranged from 0.142 to 0.727 . Delayed Memory, Immediate Memory and Visuospatial/ Constructional Indices showed strong internal reliability. Similar to a previous report [22], the
Table I. Demographic characteristics of sample

\begin{tabular}{|lcc|}
\hline Parameter & Percentage of sample & $N$ \\
\hline Gender & & \\
\hline Male & 52.1 & 123 \\
\hline Female & 47.9 & 113 \\
\hline Age [years] & & \\
\hline $62-70$ & 45.3 & 107 \\
\hline $71-77$ & 54.7 & 129 \\
\hline Education [years] & & 56 \\
\hline $1-6$ & 23.7 & 75 \\
\hline $7-9$ & 31.8 & 59 \\
\hline $10-12$ & 25.0 & 46 \\
\hline $13-18$ & 19.5 & \\
\hline
\end{tabular}

attention and Language Indices showed relatively weak reliability (see Table IV).

\section{Validity of the RBANS}

To test the concurrent validity of the RBANS subtests, correlations between each of the RBANS and MMSE subtests were conducted. The Naming Index of the MMSE scored constantly (value $=2$ ), so its correlations could not be obtained. As can be seen in Table V, the RBANS subtests demonstrated strong correlations with most of the MMSE subtests. The total score of the RBANS was highly correlated with that of the MMSE $(r=0.594$, $p<0.001)$. The Immediate Memory, Delayed Memory, and Attention indices of the RBANS showed strong correlations with most of the MMSE subtests. The Visuospatial/Constructional and Language indices were moderately correlated with a few of the MMSE subtests.

Confirmatory factor analysis was performed on the full sample of 236 individuals. The confirmatory analysis model tests the goodness of fit of the empirical data from the Chinese sample to the assumed structure of the instrument. $\chi^{2}$ (Minimum Fit Function Chi-Square)/df (degrees of freedom)

Table II. Influence of demographic characteristics on RBANS performance

\begin{tabular}{|c|c|c|c|c|c|}
\hline \multirow[t]{2}{*}{ RBANS index } & \multicolumn{2}{|c|}{ Mean (SD) } & \multirow{2}{*}{$\begin{array}{l}\text { Gender } \\
t \text { value }\end{array}$} & \multirow{2}{*}{$\begin{array}{c}\text { Age } \\
r \text { value }\end{array}$} & \multirow{2}{*}{$\begin{array}{c}\text { Education } \\
r \text { value }\end{array}$} \\
\hline & Males & Females & & & \\
\hline Total Scale & 87.99 (14.12) & $83.87(14.00)$ & $0.991^{*}$ & $-0.233^{\star * *}$ & $0.620^{\star * \star}$ \\
\hline Immediate memory & $81.64(14.18)$ & $78.80(15.19)$ & 1.488 & $-0.169^{\star *}$ & $0.483^{* * *}$ \\
\hline Visuospatial/constructional & $99.59(16.53)$ & $93.04(16.02)$ & $3.086^{\star \star}$ & $-0.165^{\star}$ & $0.475^{\star * *}$ \\
\hline Language & $93.67(9.50)$ & $93.73(10.61)$ & -0.039 & 0.012 & $0.212^{\star \star}$ \\
\hline Attention & $89.32(16.90)$ & $82.25(17.73)$ & $3.135^{\star *}$ & $-0.167^{*}$ & $0.558^{\star \star *}$ \\
\hline Delayed memory & $90.92(17.68)$ & $90.65(17.16)$ & 0.12 & $-0.279^{\star \star *}$ & $0.466^{\star * *}$ \\
\hline
\end{tabular}

${ }^{*} p<0.05,{ }^{* *} p<0.01,{ }^{* * *} p<0.001$ 
Table III. Mean and standard deviations of the RBANS

\begin{tabular}{|c|c|c|c|}
\hline & Mean (SD) & Range & $N$ \\
\hline \multicolumn{4}{|l|}{ RBANS index } \\
\hline Total score & 86.02 (14.19) & $53-120$ & 236 \\
\hline Immediate memory & $80.28(14.71)$ & $49-120$ & 236 \\
\hline $\begin{array}{l}\text { Visuospatial/ } \\
\text { constructional }\end{array}$ & $96.45(16.58)$ & 53-131 & 236 \\
\hline Language & $93.70(10.03)$ & $57-134$ & 236 \\
\hline Attention & $85.93(17.63)$ & $46-135$ & 236 \\
\hline Delayed memory & 90.79 (17.40) & 44-129 & 236 \\
\hline \multicolumn{4}{|l|}{ RBANS subtests } \\
\hline List Learning & $21.33(5.58)$ & $4-35$ & 236 \\
\hline Story Memory & $12.54(3.98)$ & $3-23$ & 236 \\
\hline Figure Copy & $18.30(2.19)$ & $8-20$ & 236 \\
\hline Line Orientation & $14.13(3.48)$ & $5-20$ & 236 \\
\hline Picture Naming & $9.60(0.75)$ & $6-10$ & 236 \\
\hline Semantic Fluency & $17.18(4.02)$ & $8-35$ & 236 \\
\hline Digit Span & $10.22(2.65)$ & $4-16$ & 236 \\
\hline Coding & $27.97(11.37)$ & $2-60$ & 236 \\
\hline List Recall & $3.53(2.75)$ & $0-10$ & 236 \\
\hline List Recognition & $18.36(1.72)$ & $10-20$ & 236 \\
\hline Story Recall & $6.59(3.02)$ & $0-12$ & 236 \\
\hline Figure Recall & $12.44(4.58)$ & $0-20$ & 236 \\
\hline
\end{tabular}

Table IV. Internal reliability of Index Scores and Total Score

\begin{tabular}{|lc|}
\hline Subtest Scores & Cronbach's $\alpha$ \\
\hline $\begin{array}{l}\text { List Learning and Story Memory } \\
\text { (Immediate Memory) }\end{array}$ & 0.567 \\
\hline $\begin{array}{l}\text { Figure Copy and Line Orientation } \\
\text { (Visuospatial/Constructional) }\end{array}$ & 0.419 \\
\hline $\begin{array}{l}\text { Picture Naming and Semantic Fluency } \\
\text { (Language) }\end{array}$ & 0.142 \\
\hline Digit Span and Coding (Attention) & 0.309 \\
\hline $\begin{array}{l}\text { List Recall, List Recognition, Story Recall, } \\
\text { Figure Recall (Delayed Memory) }\end{array}$ & 0.727 \\
\hline All subtests (Total Scale Index) & 0.806 \\
\hline
\end{tabular}

$=3.15, \mathrm{GFI}$ (goodness of fit index) $=0.91, \mathrm{CFI}$ (Comparative Fit Index) $=0.95$, IFI (Incremental Fit Index) $=0.95$, RMSEA (Root Mean Square Error of Approximation) $=0.095$, NNFI (Non-Normed Fit Index $=0.93$. Detailed information concerning the load factors can be seen in Table VI. The $t$ value is an index of parameter goodness of fit for a single model and was above 2.0 for all indices in this study. The result showed that the 5 -factor model was acceptable and could measure latent variables effectively.

\section{Discussion}

To the best of our knowledge, the present study is the first to report on the reliability and validity of the RBANS in community-dwelling elderly in China. Many previous investigations have demonstrated the utility of the RBANS for use in the evaluation of individuals' neuropsychological status and have considered its internal reliability and validity $[7,19$, 23-30]. The findings of our study are generally consistent with those of previous investigations. The cognitive status noted on the RBANS is broadly consistent with the results of other measures but is lower than the values reported by other studies [1, 2, 7-10, 19-23]. This finding may have resulted from the low level of education of the subjects in our study [8-10, 15]. The data demonstrate acceptable reliability. The internal reliability was robust as measured by most indices. Specifically, the internal reliability consistency of the RBANS index scores reported in this study was essentially the same as that reported by Duff, Gontkovsky et al. [1, 7-9, 19-23]. Thus, the study provided reliable and useful data, which suggested that the RBANS might be a useful and simple tool for the assessment of cognitive status in communitydwelling elderly.

The Mini-Mental State Examination, a very brief tool, is sufficient to document the severity of cognitive deficits in the elderly [17]. The MMSE has proven to be valuable in dementia studies, where it is used as a "standard" easily communicated and cited [3]. The MMSE also provides an interpretive context for the results in many studies. The wide use of the MMSE makes it possible to compare results across studies. The RBANS showed strong concurrent validity based upon its significant correlations with the MMSE. Most of the RBANS subtests demonstrated significant correlations with the MMSE subtests. Particularly strong were the correlations within the Immediate Memory, Delayed Memory, and Attention indices of the RBANS and most of the MMSE subtests. The RBANS subtests designed to assess memory also showed strong correlations with memory measures of the MMSE. The RBANS also showed good construct validity. Similarly, the confirmatory factor analysis conducted on the 236 community-dwelling elderly demonstrated consistently acceptable fit indices. The results of the confirmatory factor analysis indicated an acceptable fit of the Chinese version of the RBANS to the original one. Therefore, these findings demonstrate that the RBANS is commensurate with other measures known to be sensitive in community-dwelling elderly.

Previous studies have shown that the RBANS is a sensitive and clinically useful tool used to briefly screen cognitive deficits in various populations including individuals with dementia [23, 24], multiple 


\begin{tabular}{|c|c|c|c|c|c|c|c|c|c|c|c|c|c|c|c|c|c|}
\hline 总 & 龒 & $\mid$\begin{tabular}{l}
$x$ \\
\multirow{2}{*}{} \\
\multirow{2}{*}{} \\
0
\end{tabular} & 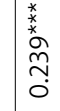 & $\begin{array}{l}* \\
\stackrel{\infty}{0} \\
\stackrel{0}{0} \\
0\end{array}$ & 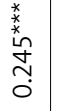 & 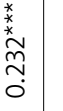 & $\begin{array}{l}\text { 絭 } \\
\stackrel{\sim}{N} \\
\stackrel{0}{0}\end{array}$ & 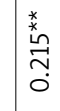 & 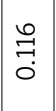 & 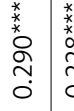 & 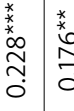 & 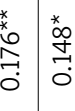 & 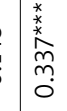 & $\mid \begin{array}{l}* \\
\overrightarrow{0} \\
0 \\
0 \\
0\end{array}$ & $\begin{array}{l}0 \\
\stackrel{2}{0} \\
0\end{array}$ & 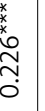 & 莡 \\
\hline 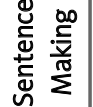 & 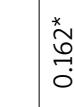 & 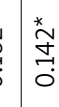 & 궁 & $\begin{array}{l}\tilde{N} \\
\stackrel{\sigma}{0} \\
0\end{array}$ & 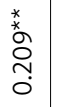 & $\begin{array}{l}\hat{f} \\
\delta \\
0 \\
0\end{array}$ & 先 & $\overrightarrow{0}$ & $\begin{array}{l}\hat{8} \\
\dot{0} \\
i\end{array}$ & 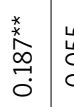 & 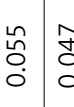 & 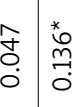 & : & $\begin{array}{l}\hat{0} \\
0 \\
\end{array}$ & $\begin{array}{l}\text { oे } \\
\text { o. }\end{array}$ & $\begin{array}{l}0 \\
0 \\
0 \\
0\end{array}$ & $\begin{array}{l}\text { ठิ } \\
\text { ¿े }\end{array}$ \\
\hline 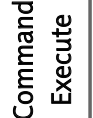 & $\begin{array}{l}\text { 类 } \\
\stackrel{2}{2} \\
\stackrel{0}{0}\end{array}$ & 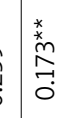 & 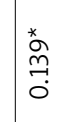 & 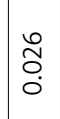 & $\begin{array}{l}\underbrace{*}_{x} \\
\stackrel{x}{\mathbb{N}} \\
0 \\
0\end{array}$ & 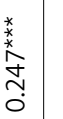 & 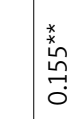 & 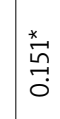 & $\begin{array}{l}\hat{\tilde{n}} \\
O \\
\dot{0}\end{array}$ & 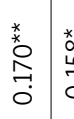 & 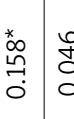 & $\begin{array}{lll}0 & * \\
0 \\
0 \\
0 \\
0 \\
0\end{array}$ & 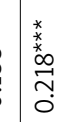 & $\mid \begin{array}{l}* \\
\overrightarrow{0} \\
0 \\
0\end{array}$ & 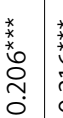 & 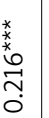 & 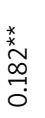 \\
\hline 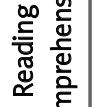 & $\begin{array}{l}* 0 \\
\stackrel{0}{0} \\
0 \\
0\end{array}$ & 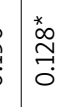 & 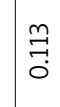 & 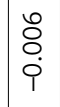 & $\begin{array}{l}\vec{\exists} \\
0\end{array}$ & 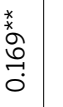 & 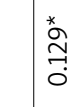 & $\underset{\nabla}{\vec{\delta}}$ & \begin{tabular}{l}
\multirow{n}{*}{} \\
$\hat{n}$ \\
0 \\
0
\end{tabular} & 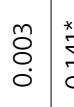 & 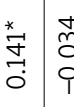 & 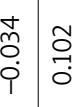 & $\begin{array}{l}* \\
0 \\
0 \\
0\end{array}$ & $\begin{array}{l}m \\
\overrightarrow{7} \\
0\end{array}$ & 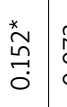 & $\begin{array}{l}n \\
\hat{o} \\
0 \\
\end{array}$ & 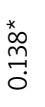 \\
\hline 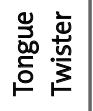 & 范 & 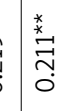 & 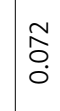 & 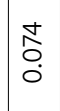 & 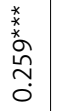 & : & 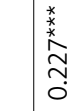 & 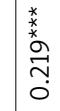 & $\begin{array}{l}0 \\
0 \\
i \\
i\end{array}$ & 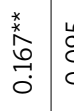 & 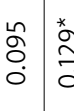 & 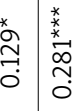 & \begin{tabular}{l}
$*$ \\
\multirow{2}{*}{} \\
0 \\
0 \\
0
\end{tabular} & $\mid \begin{array}{l}\stackrel{*}{n} \\
\stackrel{m}{0} \\
0\end{array}$ & 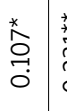 & 䓠 & $\begin{array}{l}\text { : } \\
\stackrel{0}{\circ}\end{array}$ \\
\hline 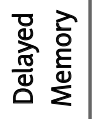 & 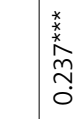 & $\mid \begin{array}{l}* \\
x \\
w \\
m \\
0 \\
0\end{array}$ & 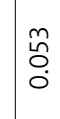 & $\begin{array}{l}\infty \\
0 \\
0 \\
0\end{array}$ & $\begin{array}{l}n \\
0 \\
0 \\
0\end{array}$ & 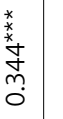 & 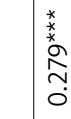 & $\begin{array}{l}x \\
x \\
x \\
o \\
0 \\
0 \\
0\end{array}$ & $\underset{0}{0}$ & 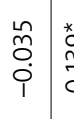 & 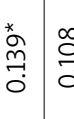 & \begin{tabular}{l|l}
$\stackrel{\overrightarrow{\tilde{m}}}{0}$ \\
0 \\
0
\end{tabular} & 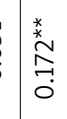 & 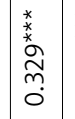 & 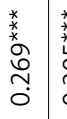 & 蒃 & مِ \\
\hline$\frac{.0}{\frac{\pi}{\pi}}$ & 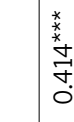 & 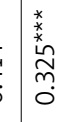 & 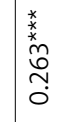 & $\begin{array}{l}\infty \\
\stackrel{\infty}{0} \\
0 \\
0\end{array}$ & 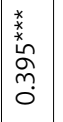 & 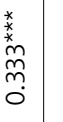 & 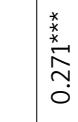 & $\begin{array}{l}\text { 类 } \\
\stackrel{0}{0} \\
\tilde{m} \\
0\end{array}$ & 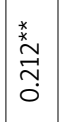 & 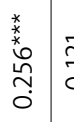 & 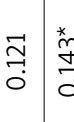 & 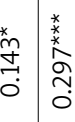 & 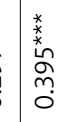 & 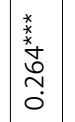 & 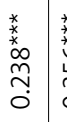 & 蒃 & 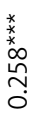 \\
\hline 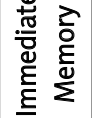 & d. & 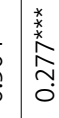 & 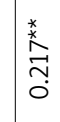 & 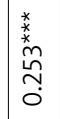 & 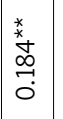 & 莣 & \begin{tabular}{l}
$\stackrel{*}{*}$ \\
$\stackrel{x}{*}$ \\
\multirow{N}{0}{} \\
0
\end{tabular} & 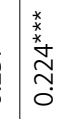 & \begin{tabular}{l}
$*$ \\
\multirow{2}{*}{} \\
$\stackrel{0}{0}$ \\
0
\end{tabular} & 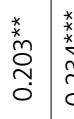 & 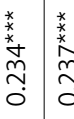 & 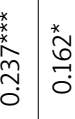 & $\begin{array}{l}* \\
\stackrel{*}{0} \\
\stackrel{0}{0}\end{array}$ & $\mid \begin{array}{l}* \\
0 \\
0 \\
0 \\
0 \\
0\end{array}$ & $\begin{array}{l}* \\
0 \\
0 \\
\\
0 \\
0\end{array}$ & 溌 & 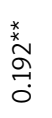 \\
\hline 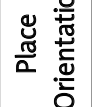 & $\begin{array}{l}* \\
\stackrel{0}{0} \\
\stackrel{0}{0}\end{array}$ & $\stackrel{\stackrel{n}{0}}{\circ}$ & 管 & $\mid \begin{array}{l}\tilde{L} \\
0 \\
0 \\
0 \\
0\end{array}$ & $\mid \begin{array}{l}\text { 总} \\
0 \\
0\end{array}$ & $\begin{array}{l}\overrightarrow{0} \\
0 \\
0 \\
0\end{array}$ & $\begin{array}{l}\text { o } \\
\text { o } \\
\text { Oे }\end{array}$ & 总 & $\begin{array}{l}\stackrel{\circ}{0} \\
\stackrel{0}{\circ}\end{array}$ & $\begin{array}{ll}0 \\
0 \\
0 \\
0\end{array}$ & 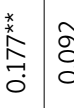 & 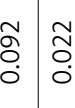 & 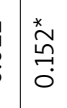 & $\mid \begin{array}{l}* \\
0 \\
0 \\
0 \\
0 \\
0\end{array}$ & $\begin{array}{l}\overrightarrow{\hat{m}} \\
0 \\
0\end{array}$ & 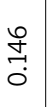 & $\begin{array}{l}\text { İ } \\
\text { ठ. }\end{array}$ \\
\hline 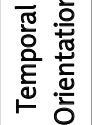 & 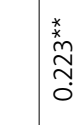 & $\begin{array}{l}\text { * } \\
\stackrel{2}{*} \\
0\end{array}$ & 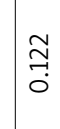 & 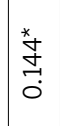 & $\mid \begin{array}{c}\text { 总 } \\
0 \\
0\end{array}$ & 莡 & 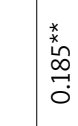 & 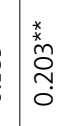 & \begin{tabular}{|l|}
0 \\
$\stackrel{2}{0}$ \\
0 \\
0
\end{tabular} & 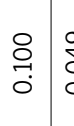 & \begin{tabular}{l|l}
0 & \multirow{2}{*}{} \\
0 & $\infty$ \\
0 & 0 \\
0 & 0
\end{tabular} & 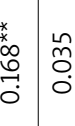 & 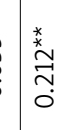 & $\mid \begin{array}{l}* \\
+ \\
\vdots \\
0 \\
0\end{array}$ & 年 & 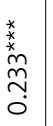 & 豙 \\
\hline 总 & 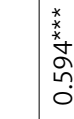 & 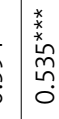 & 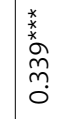 & 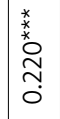 & 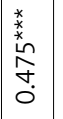 & 絭 & 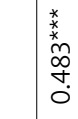 & $\mid \begin{array}{l}\frac{x}{x} \\
⿱ x \\
0 \\
0 \\
0 \\
0\end{array}$ & 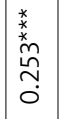 & 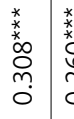 & 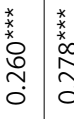 & 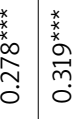 & 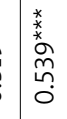 & 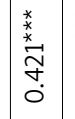 & 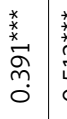 & 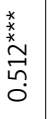 & 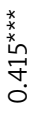 \\
\hline & 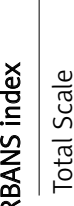 & 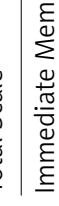 & 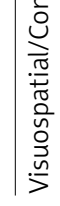 & 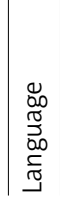 & 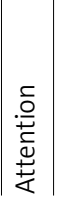 & 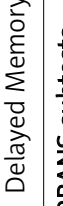 & 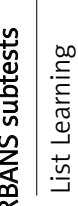 & 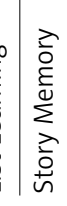 & 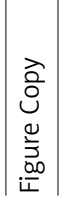 & 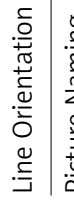 & 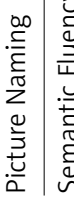 & 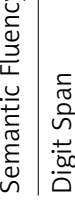 & 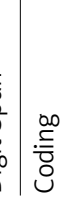 & 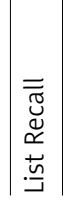 & 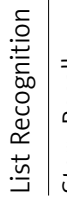 & 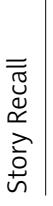 & 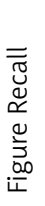 \\
\hline
\end{tabular}


Table VI. The load factor of RBANS 5-factor-model (LAMBDA-X)

\begin{tabular}{|lccccc|}
\hline & Immediate memory & $\begin{array}{c}\text { Visuospatial } \\
\text { constructional }\end{array}$ & Language & Attention & Delayed memory \\
\hline List Learning & 0.62 & - & - & - & - \\
\hline Story Memory & 0.67 & - & - & - & - \\
\hline Figure Copy & - & 0.50 & - & - & - \\
\hline Line Orientation & - & 0.58 & - & - & - \\
\hline Picture Naming & - & - & 0.43 & - & - \\
\hline Semantic Fluency & - & - & 0.49 & 0.44 & - \\
\hline Digit Span & - & - & - & 0.94 & - \\
\hline Coding & - & - & - & - & 0.70 \\
\hline List Recall & - & - & - & - & 0.83 \\
\hline List Recognition & - & - & - & - & 0.60 \\
\hline Story Recall & - & - & - & - & 0.57 \\
\hline Figure Recall & - & - & - & - & - \\
\hline
\end{tabular}

sclerosis [25], Parkinson's disease [26, 27], Huntington's disease [5, 26, 28], stroke [29-32], traumatic brain injury $[22,33]$, schizophrenia [6, 34-37], bipolar disorder [34, 38] and anorexia nervosa [39]. The results of the current study add to recent research that has supported the wide use and clinical utility of the RBANS in the neuropsychological screening of various populations. In addition to the strong psychometric properties shown in present and previous studies, the short administration time, normative index scores, and alternate forms of the RBANS [22] support its wide use in the cognitive evaluation of the elderly in the future.

Several potential limitations of this study must be highlighted. First, the current sample consisted of individuals from three communities around Tongji hospital in Shanghai, China. The generalization of these results may be limited. As a result, this research would benefit from replication in other populations with differing cognitive status and demographic characteristics. For instance, future research might explore whether the utility of the RBANS differs in different areas. Second, the current study utilized the MMSE to test the validity of the RBANS. Although the findings are promising, the relevant research would be strengthened by further comparison of the subtests with other neuropsychological measures considered to assess similar cognitive domains (e.g., comparison of the Figure Copy and its Delay trial to the Rey Complex Figure Test and its memory indices). Third, we did not collect the test-retest data, which would be a good proof of reliability. We could not prove it in this manuscript. Nevertheless, the present study contributes to the literature supporting the use of the RBANS in Chinese community-dwelling elderly samples. The Chinese translation and adaptation of the RBANS demonstrated satisfactory reliability and validity. Further studies to link more data in different samples are necessary.

In conclusion, following the results of the present study, it can be concluded that the Chinese version of the RBANS had relatively good reliability and validity in a community-dwelling elderly sample. It may be a useful screening instrument for cognitive assessment in Chinese community-dwelling elderly.

\section{Acknowledgments}

The work was supported by the National Natural Science Foundation of China (Grant No. 30770769, to Chunbo Li) and the Natural Science Foundation of Shanghai, China (Grant No. 06ZR14086, to Chunbo Li).

\section{References}

1. Duff K, Schoenberg MR, Patton D, et al. Regression-based formulas for predicting change in RBANS subtests with older adults. Arch Clin Neuropsychol 2005; 20: 281-90.

2. Joray S, Wietlisbach V, Bula CJ. Cognitive impairment in elderly medical inpatients: detection and associated six-month outcomes. Am J Geriatr Psychiatry 2004; 12: 639-47.

3. Woodford HJ, George J. Cognitive assessment in the elderly: a review of clinical methods. QJM 2007; 100: 469-84.

4. Magierki R, Sobów T, Karlińska I, Flirski M, Kłoszewska I. Clinical and neuropsychological predictors of the diagnosis of dementia with Lewy bodies. Arch Med Sci 2007; 3: 157-63.

5. Randolph C, Tierney MC, Mohr E, Chase TN. The Repeatable Battery for the Assessment of Neuropsychological Status (RBANS): preliminary clinical validity. J Clin Exp Neuropsychol 1998; 20: 310-9.

6. Wilk CM, Gold JM, Humber K, Dickerson F, Fenton WS, Buchanan RW. Brief cognitive assessment in schizophrenia: normative data for the Repeatable Battery 
for the Assessment of Neuropsychological Status. Schizophr Res 2004; 70: 175-86.

7. Duff K, Beglinger LJ, Schoenberg MR, et al. Test-retest stability and practice effects of the RBANS in a community dwelling elderly sample. J Clin Exp Neuropsychol 2005; 27: 565-75.

8. Duff K, Patton D, Schoenberg MR, Mold J, Scott JG, Adams $\mathrm{RL}$. Age and education corrected independent normative data for the RBANS in a community dwelling elderly sample. Clin Neuropsychol 2003; 17: 351-66.

9. Gontkovsky ST, Mold JW, Beatty WW. Age and educational influences on RBANS index scores in a nondemented geriatric sample. Clin Neuropsychol 2002; 16: 258-63.

10. Beatty WW, Mold JW, Gontkovsky ST. RBANS performance: influences of sex and education. J Clin Exp Neuropsychol 2003; 25: 1065-9.

11. Wysokiński A, Zboralski K, Orzechowska A, Gałecki P, Florkowski A, Talarowska M. Normalization of the verbal fluency test on the basis of results for healthy subjects, patients with schizophrenia, patients with organic lesions of the chronic nervous system and patients with type 1 and 2 diabetes. Arch Med Sci 2010; 6: 438-46.

12. Shulman KI, Herrmann N, Brodaty $\mathrm{H}$, et al. IPA survey of brief cognitive screening instruments. Int Psychogeriatr 2006; 18: 281-94.

13. Folstein MF, Folstein SE, McHugh PR. "Mini-mental state", A practical method for grading the cognitive state of patients for the clinician. J Psychiatr Res 1975; 12: 189-98.

14. Swain DG, O'Brien AG, Nightingale PG. Cognitive assessment in elderly patients admitted to hospital: the relationship between the Abbreviated Mental Test and the Mini-Mental State Examination. Clin Rehabil 1999; 13: 503-8.

15. Li C, Wu W, Jin H, et al. Successful aging in Shanghai, China: definition, distribution and related factors. Int Psychogeriatr 2006; 18: 551-63.

16. Katzman R, Zhang MY, Ouang-Ya-Qu, et al. A Chinese version of the Mini-mental State Examination: impact of illiteracy in a Shanghai dementia survey. J Clin Epidemiol 1988; 41: 971-8.

17. Tombaugh TN, Mclntyre NJ. The mini-mental state examination: a comprehensive review. J Am Geriatr Soc 1992; 40: 922-35.

18. Randolph C. Repeatable Battery for the Assessment of Neuropsychological Status Manual. San Antonio, TX: Psychological Corporation 1998.

19. Duff K, Schoenberg MR, Mold JW, Scott JG, Adams RL. Normative and retest data on the RBANS cortical/ subcortical index in older adults. J Clin Exp Neuropsychol 2007; 29: 854-9.

20. Patton DE, Duff K, Schoenberg MR, Mold J, Scott JG, Adams RL Base rates of longitudinal RBANS discrepancies at one- and two-year intervals in community-dwelling older adults. Clin Neuropsychol 2005; 19: 27-44.

21. Duff K, Schoenberg MR, Patton D, Mold J, Scott JG, Adams RL. Predicting change with the RBANS in a community dwelling elderly sample. J Int Neuropsychol Soc 2004; 10: 828-34.

22. McKay C, Casey JE, Wertheimer J, Fichtenberg NL. Reliability and validity of the RBANS in a traumatic brain injured sample. Arch Clin Neuropsychol 2007; 22: 91-8.

23. Duff K, Humphreys Clark JD, O'Bryant SE, Mold JW, Schiffer RB, Sutker PB. Utility of the RBANS in detecting cognitive impairment associated with Alzheimer's disease: sensitivity, specificity, and positive and negative predictive powers. Arch Clin Neuropsychol 2008; 23: 603-12.
24. Garcia C, Leahy B, Corradi K, Forchetti C. Component structure of the Repeatable Battery for the Assessment of Neuropsychological Status in dementia. Arch Clin Neuropsychol 2008; 23: 63-72.

25. Aupperle RL, Beatty WW, Shelton Fde N, Gontkovsky ST. Three screening batteries to detect cognitive impairment in multiple sclerosis. Mult Scler 2002; 8: 382-9.

26. Beatty WW, Ryder KA, Gontkovsky ST, Scott JG, McSwan $\mathrm{KL}$, Bharucha KJ. Analyzing the subcortical dementia syndrome of Parkinson's disease using the RBANS. Arch Clin Neuropsychol 2003; 18: 509-20.

27. Yang C, Garrett-Mayer E, Schneider JS, Gollomp SM, Tilley BC. Repeatable battery for assessment of neuropsychological status in early Parkinson's disease. Mov Disord 2009; 24: 1453-60.

28. Beglinger LJ, Duff K, Allison J, et al. Cognitive change in patients with Huntington disease on the Repeatable Battery for the Assessment of Neuropsychological Status. J Clin Exp Neuropsychol 2009: 1-6.

29. Larson E, Kirschner K, Bode R, Heinemann A, Goodman R. Construct and predictive validity of the repeatable battery for the assessment of neuropsychological status in the evaluation of stroke patients. J Clin Exp Neuropsychol 2005; 27: 16-32.

30. Wilde MC. The validity of the repeatable battery of neuropsychological status in acute stroke. Clin Neuropsychol 2006; 20: 702-15.

31. Wagle J, Farner L, Flekkoy K, et al. Cognitive impairment and the role of the ApoE epsilon4-allele after stroke-a 13 months follow-up study. Int J Geriatr Psychiatry 2010; 25: 833-42.

32. Wagle J, Farner L, Flekkoy K, et al. Association between ApoE epsilon4 and cognitive impairment after stroke. Dement Geriatr Cogn Disord 2009; 27: 525-33.

33. McKay C, Wertheimer JC, Fichtenberg NL, Casey JE. The repeatable battery for the assessment of neuropsychological status (RBANS): clinical utility in a traumatic brain injury sample. Clin Neuropsychol 2008; 22: 228-41.

34. Dickerson F, Boronow JJ, Stallings C, Origoni AE, Cole SK, Yolken RH. Cognitive functioning in schizophrenia and bipolar disorder: comparison of performance on the Repeatable Battery for the Assessment of Neuropsychological Status. Psychiatry Res 2004; 129: 45-53.

35. Iverson GL, Brooks BL, Haley GM. Interpretation of the RBANS in inpatient psychiatry: clinical normative data and prevalence of low scores for patients with schizophrenia. Appl Neuropsychol 2009; 16: 31-41.

36. Keri S, Kelemen $\mathrm{O}$. The role of attention and immediate memory in vulnerability to interpersonal criticism during family transactions in schizophrenia. Br J Clin Psychol 2009; 48: 21-9.

37. Smith RC, Lindenmayer JP, Davis JM, et al. Cognitive and antismoking effects of varenicline in patients with schizophrenia or schizoaffective disorder. Schizophr Res 2009; 110: 149-55.

38. Dittmann S, Seemuller F, Schwarz MJ, et al. Association of cognitive deficits with elevated homocysteine levels in euthymic bipolar patients and its impact on psychosocial functioning: preliminary results. Bipolar Disord 2007; 9: 63-70.

39. Mikos AE, McDowell BD, Moser DJ, et al. Stability of neuropsychological performance in anorexia nervosa. Ann Clin Psychiatry 2008; 20: 9-13. 